\title{
CHARACTER RECOGNITION THROUGH WILD ASSOCIATION: AN ALTERNATIVE IN LEARNING CHINESE SCRIPT FOR BEGINNERS
}

\author{
Kai-Chee LAM $^{1}$ \\ Faculty of Language and Communication, \\ Universiti Malaysia Sarawak (UNIMAS), Kota Samarahan \\ Lay-Hoon ANG ${ }^{2}$ \\ Department of Foreign Languages, \\ Faculty of Modern Languages and Communication, \\ Universiti Putra Malaysia, UPM Serdang \\ Wee-Ling KUAN ${ }^{3}$ \\ Faculty of Language and Communication, \\ Universiti Malaysia Sarawak (UNIMAS), Kota Samarahan \\ Foo-Terng HOE ${ }^{4}$ \\ Akademi Pengajian Bahasa, Universiti Teknologi MARA (Pulau Pinang), \\ Jalan Permatang Pauh, Permatang Pauh, Pulau Pinang \\ ${ }^{1}$ kclam@unimas.my* \\ 2 hlang@upm.edu.my \\ 3 wlkuan@unimas.my \\ ${ }^{4}$ fthoe@yahoo.com
}

Manuscript received 22 December 2017

Manuscript accepted 15 March 2018

\begin{abstract}
Learning Chinese characters can be a daunting experience for the non-native learners. This quantitative study aims to experiment the effectiveness of 'Wild Association' on learners' ability to learn Chinese characters, and to determine whether these learners who use 'Wild Association' demonstrate higher achievement in character recognition and character writing compared to learners who study Chinese characters by drilling. Consisting of 98 learners from the elementary level of Mandarin proficiency course in UNIMAS, the learners used their own imagination to learn Chinese characters, and at the same time, relating their own experience in doing so. Learners' performance was measured through the pre-test and post-test in
\end{abstract}


the form of dictation and character-recognition worksheet. The results indicate that 'Wild Association' is effective in helping learners to recognise and write characters, and is especially more effective in helping learners to recognise characters. However, learners who underwent traditional drilling approach still outperformed those who employed 'Wild Association'. It can be concluded that 'Wild Association' is a possible alternative for teaching characters in the initial stage, when characters are still foreign to learners. The result implies that 'Wild Association' suits the learning style of learners nowadays.

Keywords: reading, writing, Chinese characters, non-native learners, imagination, association

\section{Introduction}

Despite their well-known uniqueness such as being the longest continuously used writing system in the world (Zhou, 2014), highly concise and expressive, Chinese characters are also commonly known for their obvious drawbacks such as hard to recognise, remember, learn and write (Feng, 2004; Sung, 2014; Zhao, 1985). Such viewpoints then lead to the arguments on how best to teach Chinese characters.

The traditional way of teaching Chinese characters to Chinese children has always been memorising some most basic characters (such as $\{$ 'human' or $\square$ 'mouth') before applying such knowledge into the learning of more complex characters (such as 他 'he', 们 'indicating plural', 你 'you' and 叫 'call', 咬 'bite', 吃 'eat'). More often than not, prior to the learning of characters, Chinese children would have possessed some ability in speaking the language. Therefore, this approach can work for them. However, it hardly works for the non-native learners in a local national university setting such as Universiti Malaysia Sarawak (UNIMAS), who hardly know anything about this language. Time constraint is the major challenge as they merely take up the language as an elective subject for one semester (14 weeks) (Lam \& Hoe, 2013). Within that one semester, learners will be exposed to a number of high-frequency characters, which may or may not come from the category of basic characters indicated earlier. For example, the characters for one of the most frequently used phrases in Mandarin, 谢谢 'thank you', are not even from the basic characters category. This is the reason why it would be naïve for one to imagine that non-native learners can learn Chinese characters the same way as the native Chinese do (Lam, Ang, Damien, \& Hoe, 2017). In order to enable the non-native learners to start learning characters within a 14-week-long semester, innovative approaches have to be employed.

Many studies suggesting a wide array of approaches to teach Chinese characters to non-native learners have been conducted. These studies include parts analysis, contrastive analysis and characters riddles guessing (He, 2008), emphasise the radical structure (Kuo et al., 2015; Taft \& Chung, 1999; Tong \& Yip, 2015), memory strategies, examine the writing system of learners' first language (Lin \& Collins, 2012), and utilise digital tools (McLaren \& Bettinson, 2015, 2016). One of the way to teach Chinese characters is to utilise the pictographic (象形) properties of Chinese characters. The noun form for pictographic is pictograph. Pictograph is the drawing of an object according to its shape (Zhou, 2014). A number of Chinese 
characters evolved from object, such as 人 for human, 口 for mouth, 山 for mountain, 日 for sun, 月 for moon, and 木 for wood, hence, they are said to have pictographic properties (Figure 1).

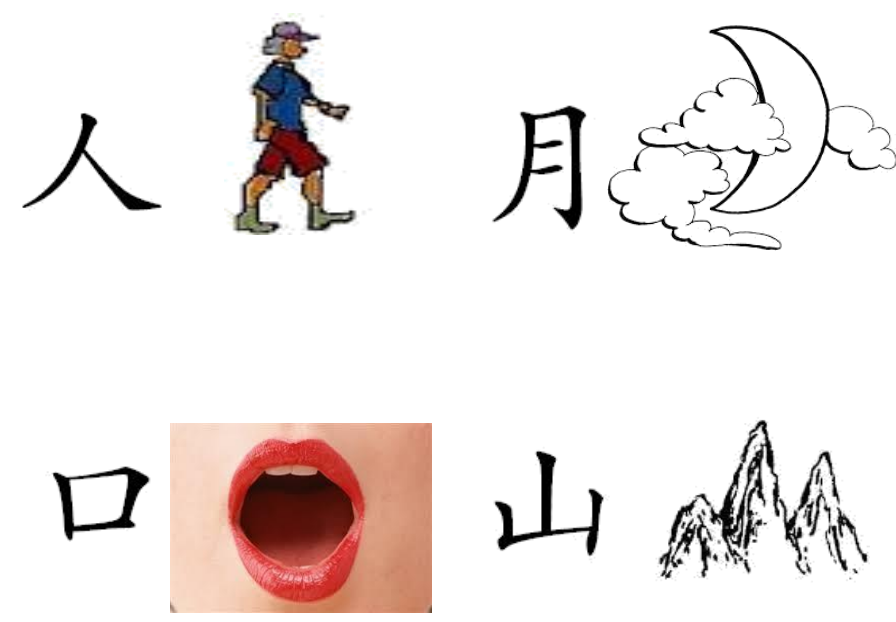

Figure 1. Examples of characters evolving from object

While there are other properties such as ideographic (指事), compound ideographic (会意), and phono-semantic compounds (形声) possessed by Chinese characters, many basic characters fall under pictographs. Although it has been reported that Chinese characters, which are pictographic total up to only around 600 , their influence cannot be ignored as they form the basis for characters which are ideographic, compound ideographic and phono-semantic compounds in nature (Shen, 2008; Zhou, 2014). Most importantly, focussing on the pictographic properties of characters can serve as the most fundamental function of jumpstarting and raising the interest of learners - including non-native learners - in learning Chinese characters.

There are a number of Chinese character teaching approaches utilising the pictographic properties of Chinese characters. One of them is to let learners to have their imaginations run wild (Kuo \& Hooper, 2004; Lam, 2011; Unger, 1991; Xu, 2003). When learners use their own imagination to learn Chinese characters - and, at the same time, relating their own experience in doing so - they can learn faster and more effectively (Li, 1994; Liu, 2005). The learners' imaginations need not relate to the etymology (the study of the sources and development of words) of the Chinese characters - as zero beginners are not expected to know the etymology. They are encouraged to come out with their own stories or provide rationales of why, for example, 人 means human, or 鱼 means fish. Such approach is termed as 'Wild Association' (Lam, 2011). It can make the teaching-learning of Chinese characters to take place in a more interesting, interactive and meaningful way.

Figure 2 shows an example of the association between the character 看 'see/look' and the imagination of a learner from an elementary class (Level 1). It can be clearly seen that if it is associated properly and creatively, 'Wild Association' can trigger and stimulate learners' desire to learn. 


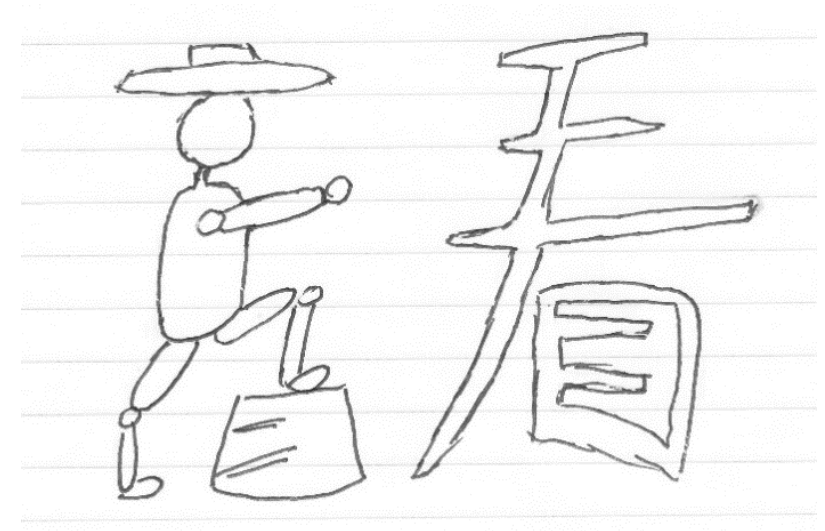

Figure 2. 'Wild Association' associating the character 看 'see/look' and learner's imagination

\section{Research Objectives}

1. To investigate and compare the effectiveness of 'Wild Association' in helping learners to

(a) recognise characters, and to

(b) write characters.

2. To determine whether learners who use 'Wild Association' demonstrate higher achievement in character recognition and character writing compared to learners who study characters by drilling.

\section{Methodology}

\section{When and Who}

'Wild Association' was incorporated into our Level 1 (elementary) Mandarin lesson in week 9 of a normal semester. Learners who were involved in the experiment were chosen from five groups. Our learners were already exposed to a number of Chinese characters in week 9 of a semester. Nevertheless, their performance varied. Some of them could write certain characters, which have fewer strokes, and some of them could only recognise certain characters without being able to write them. As a result, their overall motivation went down slightly. That is why we chose that period to introduce the 'Wild Association' approach because it can boost their spirits besides arousing their interest. It could be relatively less relevant to introduce this approach earlier as the number of characters introduced to the learners are considered limited, hence reducing the desired impact of such teaching approach.

Three weeks prior to the experiment, the performance of learners from these five groups in both character recognition and writing were measured through pre-test. Such pre-test came in the form of character-recognition worksheet and character-writing test (dictation). 
Three weeks later, out of the five groups of learners, four groups underwent the 'Wild Association' session, in which after the session, two of these groups had their characters writing ability measured, while the other two groups had their characters recognition ability measured. The remaining one group was classified as a control group (Table 1) and did not undergo the 'Wild Association' session. Instead, drilling approach under traditional teaching was applied to this group. The ability of this group on characters recognition and writing was also measured at the end of the semester. A total of 98 learners' performance were gathered, after excluding those who were absent either during pre-test, 'Wild Association' session, or posttest.

Table 1

Details of participating groups (learners)

\begin{tabular}{|c|c|c|c|c|}
\hline Group & $\begin{array}{l}\text { Number } \\
\text { of } \\
\text { learners } \\
\text { (N) }\end{array}$ & Pre-test & $\begin{array}{l}\text { Underwent 'Wild } \\
\text { Association' } \\
\text { session? }\end{array}$ & Post-test \\
\hline 1 & 21 & Character writing & Yes & Character writing \\
\hline 3 & 16 & Character writing & Yes & Character writing \\
\hline 2 & 22 & $\begin{array}{l}\text { Character } \\
\text { recognition }\end{array}$ & Yes & $\begin{array}{l}\text { Character } \\
\text { recognition }\end{array}$ \\
\hline 4 & 17 & $\begin{array}{l}\text { Character } \\
\text { recognition }\end{array}$ & Yes & $\begin{array}{l}\text { Character } \\
\text { recognition }\end{array}$ \\
\hline 5 & 22 & $\begin{array}{l}\text { Character writing } \\
\text { and recognition }\end{array}$ & $\begin{array}{c}\text { No } \\
\text { (control group) }\end{array}$ & $\begin{array}{l}\text { Character writing } \\
\text { and recognition }\end{array}$ \\
\hline
\end{tabular}

\section{How}

The actual incorporation of the approach in class is as follows:

In an effective classroom, there should be a certain amount of time allocated for 'teacher's time' and 'learners' time'. 'Teacher's time' is the time reserved for teacher to deliver his/her teaching content and input, while 'learners' time' is the time for learners to get hands on activities in order to promote active learning.

For this study, 'teacher's time' occupied 40 minutes, leaving the remaining 70 minutes as 'learners' time'. During the first 40 minutes, we did our talking and introduced 'Wild Association' to learners. The actual 'Wild Association' came in during 'learners' time'. For 'learners' time', 20 characters which learners had been exposed to since the early of the semester, namely 你，们，吗，忙，局，很，困，对，这， 没，再，老，有，起，冷，高，邮，觉，饿，and和，were pre-determined. Learners were then divided into groups of three, with each group getting $2 \sim 3$ characters (with meanings written aside). The characters were different for each group. They were then told to relax, after which they were made clear of their task, i.e. to use own imagination and experience to associate the characters they had in hand with their meaning. The greater their imagination or association, the better the effect will be. 
Examples of 'Wild Association' (Figure 2) were shown using power point slides to stimulate their senses.

After 30 minutes, each group was asked to present their 'Wild Association'. It was expected that learners would come out with funny associations that promoted classroom interaction. The learners enjoyed listening to the 'Wild Association' (i.e. stories) from their peers. While a learner was presenting, his/her team member was asked to write the character in question on white board to let the others see how they related the character with their 'Wild Association'. The remaining learners were asked to try write down the character together. Such activity promoted in-class practice and active learning, which reinforced the entire learning in class.

Towards the end of the lesson, teacher conducted a post-test. The post-test varied according to each group. For learners of Group 1 and 3, the test came in the form of dictation, in which all 20 characters came from the presentation in class. Its purpose was to measure again learners' character writing ability. As for learners of Group 2 and 4, they were asked to write down and present the meaning of all 20 characters in class in order to measure again their character recognition ability. The lesson ended by asking the learners' opinions on such learning approach. They were generally positive towards it and were eager to try out such approach with other characters.

\section{Results and Discussion}

Prior to participation in 'Wild Association', learners' achievements in abilities of character recognition and character writing were generally lower (Figure 3), despite certain characters (such as 你 'you', 很 'very' and 吗 'question particle') were introduced to learners since the first few lessons of the semester. Such approach seemed to be more appealing or familiar to them, and hence showed better pre-test results. Nevertheless, after going through 'Wild Association' approach, both abilities demonstrated overall improvements. In other words, 'Wild Association' as an intervention approach proved its value in helping learners to recognise and write characters. 


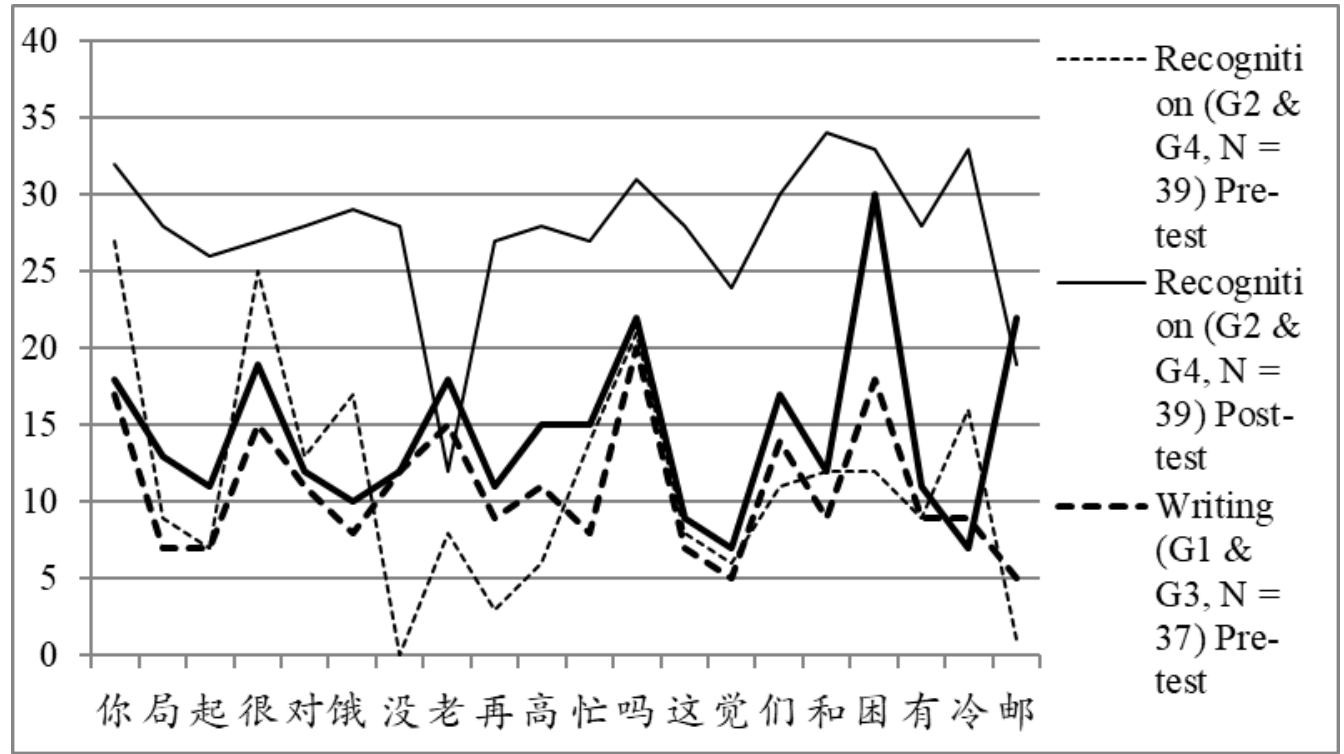

Figure 3. Effectiveness of 'Wild Association' in helping learners to recognise/write characters

However, after taking a closer look, one will observe that learners' character recognition ability was greatly and obviously elevated using 'Wild Association'. This could be due to the nature of 'Wild Association' that primarily presents an image in front of learners; hence stimulates their sense of sight. Since character recognition requires the sense of sight, 'Wild Association' has proven to be a relevant approach. Character writing ability, on the other hand, relies more on productive ability. Hence, with the relatively smaller improvements demonstrated by character writing ability, it can be concluded that 'Wild Association' is more effective in helping learners to recognise characters.

Interestingly, and rather surprisingly, both groups of learners who underwent 'Wild Association' did not demonstrate higher achievements in the posttest for characters recognition (Figure 4). Instead, their peers in the control group who studied through drilling approach scored better. If we map this finding with learners' achievements in character writing (Figure 5), similar pattern is found in which the control group also demonstrated slightly better achievements in the posttest of character writing if compared with those who underwent 'Wild Association'. In short, generally, those who underwent traditional drilling approach outperformed those who underwent 'Wild Association'. 


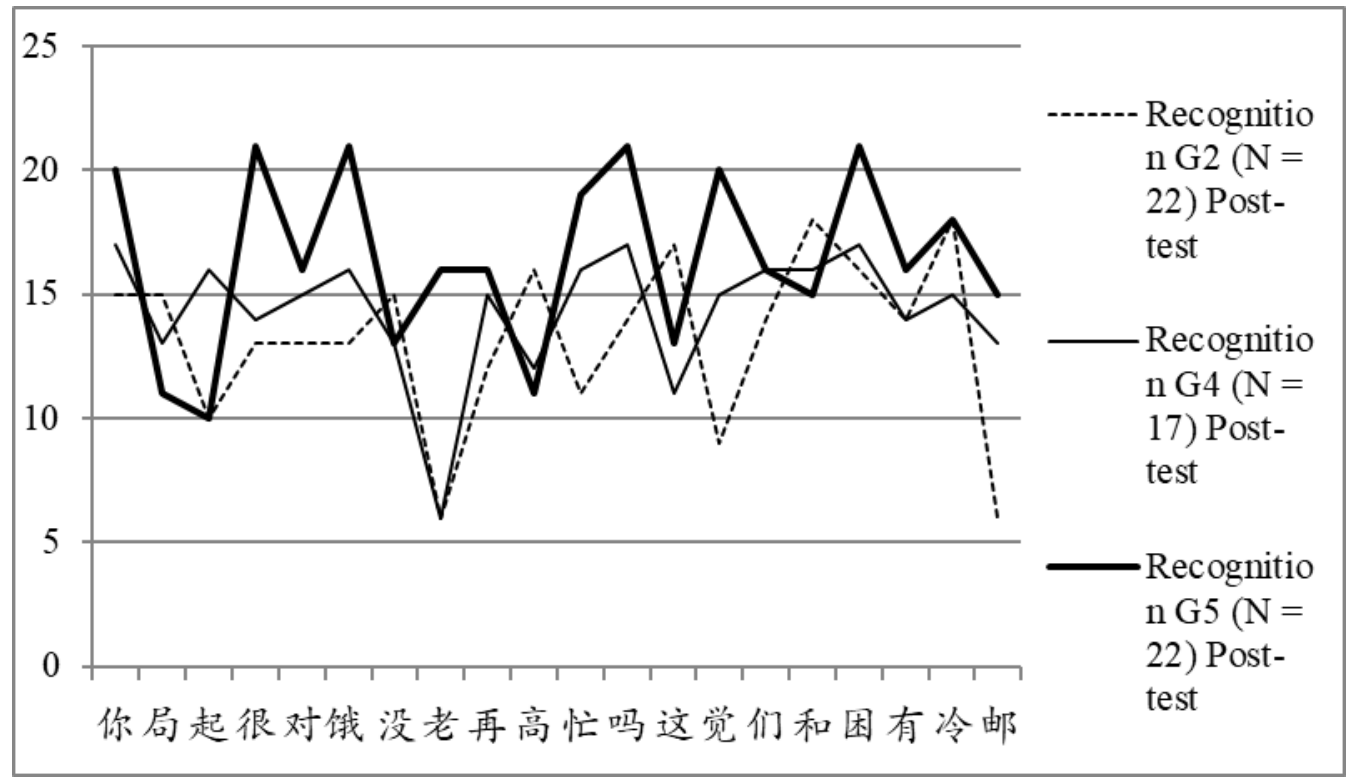

Figure 4. Comparison of achievements in character recognition among learners who underwent 'Wild Association' and learners who studied characters by drilling

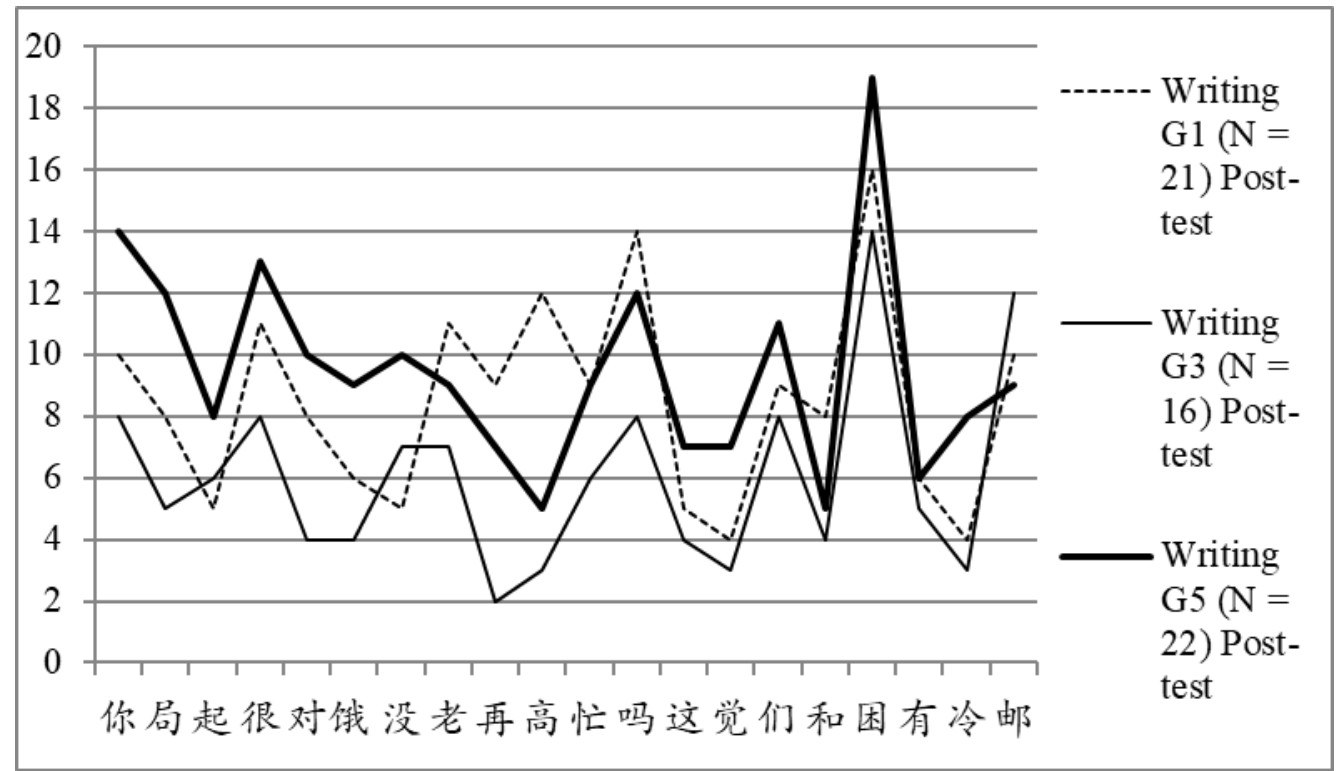

Figure 5. Comparison of achievements in character writing among learners who underwent 'Wild Association' and learners who studied characters by drilling

Such findings suggest that the traditional drilling approach still plays an important role in learning Chinese characters, but this should not disregard the credits of 'Wild Association'. Learners' creativity and ability to associate are the two crucial variables in ensuring a positive outcome in conducting such approach. Considering that 'Wild Association' requires learners to come out with own imagination and association, instructors are not supposed to intervene or offer associations to learners. The rationale being that own-created association based on 
one's experience can better impress the learner. Learners need to utilise their own cognitive skills throughout the whole process. Learners who are anxious or not relaxed and hence unable to associate will defeat the purpose of such approach. It can be seen from Figure 3, 4 and 5 that underachievement was found in pre-test and post-test for certain characters like 老 'indicating respect', 觉 'feel', 邮 'related to post', 冷 'cold' even though learners had gone through 'Wild Association'. Based on instructors' observations, these characters that are harder to generate associations and would require more creativity from the learners.

One limitation of this study would be the number of learners taking 'Wild Association'. During this particular semester, UNIMAS offered five groups of Level 1 (elementary) Mandarin classes; hence this is the maximum number of groups we could conduct our experiment. It would be better if the study could be done with bigger sample size in order to obtain a better result.

\section{Conclusion}

'Wild Association' is a possible alternative for teaching characters at least in the initial stage, especially when those characters are still foreign to learners. It can boost learners' interests and keep them moving, while minimise their fear towards learning those characters. However, when they are more familiar with the characters, the traditional drilling approach is still a preferred choice. However, it does not mean that 'Wild Association' cannot be used in teaching characters writing, since neither the traditional drilling approach nor 'Wild Association' is exclusive to any particular course. Incorporating both approaches is the best way, considering that it can suit the learning styles of different learners, especially majority of these learners are visual learners, as encountered by instructors nowadays. As learners generally reacted positively towards the use of 'Wild Association' in class, it implies that such approach suits the learners' learning style who prefer hands-on activities as well as interactions. In addition, the study shows that characters learning can also be fun for the non-native learners. Understandably, some may not agree to use 'Wild Association' as it is not the traditional approach, but considering the background and instrumental learning needs of non-native learners, the fun and inclass participation-promoting 'Wild Association' is still undoubtedly an alternative. More in-depth studies such as examining the effectiveness of 'Wild Association' across learners in the beginner and elementary levels, looking into the possibilities of retaining learners' performance after they have tried out 'Wild Association', and exploring students' perception towards the approach could be conducted to find out more about the potential of this approach.

\section{References}

Feng, T. (2004). Hanzi wenhuaquan chuyi [A discussion on Sinosphere]. Jishou Daxue Xuebao, $2,1$.

$\mathrm{He}$ Q. (2008). Character learning strategies and teaching methods research of EuroAmerican students in primary stage. Master's thesis, Xiamen University, Xiamen. 
Kuo, L. J., Kim, T. J., Yang, X., Li, H., Liu, Y., Wang, H., ... Li, Y. (2015). Acquisition of Chinese characters: The effects of character properties and individual differences among second language learners. Frontiers in Psychology, 6, 110.

Kuo, M., \& Hooper, S. (2004). The effects of visual and verbal coding mnemonics on learning Chinese characters in computer-based instruction. ETR \& $D, 52(3)$, 23-38.

Lam, H. C. (2011). A critical analysis of the various ways of teaching Chinese characters. Electronic Journal of Foreign Language Teaching, 8(1), 57-70.

Lam, K. C., \& Hoe, F. T. (2013). Shuo Malai yu xuesheng de Hanyu jiaocai: Yi Shalayue Daxue wei li [Mandarin classroom materials for Malay-speaking students - a case in UNIMAS]. Overseas Chinese Education, 68, 284-289.

Lam, K. C., Ang, L. H., Damien, M., \& Hoe, F. T. (2017). Waiyu jiaoshi yan zhong de jiaoxue fanyi: Yi chuji Duiwai Hanyu ketang wei li [The use of translation approach in teaching Chinese as a foreign language: What say you, teachers?]. Overseas Chinese Education, 93, 1411-1420.

Li, W. (1994). Qite lianxiang shizifa de shiyan yanjiu [An experimental study on wild imagination in recognising characters]. Hebei Jiaoyu, 1, 17-18.

Lin, C. H., \& Collins, P. (2012). The effects of L1 and orthographic regularity and consistency in naming Chinese characters. Reading and Writing, 25(7), 17471767.

Liu, Y. N. (2005). Fei Hanzi wenhuaquan liuxuesheng Hanzi renzhi nandian ji jiaoxue celue [The difficulties and teaching strategies in recognising Chinese characters for students coming from non-Sinospehre regions]. Kaifeng Daxue Xuebao, 19(2), 45-47).

McLaren, A. E., \& Bettinson, M. (2015). Impact of e-technologies on Chinese literacy programs for college second language learners. Electronic Journal of Foreign Language Teaching, 12(1), 101-114.

McLaren, A. E., \& Bettinson, M. (2016). Digital tools for Chinese character acquisition and their impact on student motivation. In R. Moloney \& H. Xu (Eds.), Exploring innovative pedagogy in the teaching and learning of Chinese as a foreign language (pp. 235-251). Singapore: Springer.

Shen, S. (2008). Shuo xiangxing zi [On pictograph]. Zhangzhou Shifan Xueyuan Xuebao, 4, 100-103.

Sung, K. (2014). Novice learners' Chinese-character learning strategies and performance. Electronic Journal of Foreign Language Teaching, 11(1), 38-51.

Taft, M., \& Chung, K. (1999). Using radicals in teaching Chinese characters to second language learners. Psychologia, 42, 243-251.

Tong, X., \& Yip, J. H. Y. (2015). Cracking the Chinese character: Radical sensitivity in learners of Chinese as a foreign language and its relationship to Chinese word reading. Reading and Writing, 28(2), 159-181.

Unger, J. M. (1991). Memorizing kanji: Lessons from a pro. Sino-Platonic Papers, 27, 49-58.

$\mathrm{Xu}, \mathrm{Z}$. (2003). Hanzi beijing yu Hanyu renzhi [Chinese characters background and knowing Chinese characters]. Chinese Language Learning, 6, 63-67. 
Zhao, L. (1985). Yu Lading wenzi xiangbi Hanzi juyou si da youdian [The four strengths of Chinese characters compared with Roman alphabets]. Zhongxue Yuwen, 6, 21.

Zhou, Z. (2014). The six principles of Chinese writing and their application to design as design idea. Studies in Literature and Language, 8(3), 84-88. 